\title{
Gametocytaemia in Senegalese ChildRen WITH UNCOMPLICATED FALCIPARUM MALARIA TREATED WITH CHLOROQUINE, AMODIAQUINE OR SULFADOXINE + PYRIMETHAMINE
}

\author{
SOKHNA C.S.*, TRAPE J.-F.* \& ROBERT V.**
}

\section{Summary :}

Plasmodium falciparum gametocytaemia was studied in 266 Senegalese children (median 4 years, range 0.5-16) with uncomplicated malaria treated with chloroquine $(C Q)$, amodiaquine $(A Q)$ or sulfadoxine+pyrimethamine $(S P)$. The proportion of resistant infections in vivo to these drugs was $44 \%, 16 \%$ and $7 \%$, respectively. Gametocytes were counted by microscopy in thick smears on days $0,4,7$ and 14 after treatment. There was a peak of gametocytaemia one week after treatment; on days 0,7 and 14 the gametocyte prevalences were $35 \%, 73 \%$ and $63 \%$, and the geometric means of gametocyte densities were $1.3,12.5$ and $5.6 / \mu \mathrm{L}$ of blood. Three factors were found to influence gametocytaemia: treatment, efficacy of treatment, and duration of symptoms before treatment. Gametocyte prevalence and density significantly appeared higher in children treated with $\mathrm{SP}$ than with $C Q$, and higher with $C Q$ than with $A Q$. Gametocyte prevalence and density were higher in resistant than in sensitive infections. The period between the appearance of the first clinical symptoms and treatment was positively and significantly linked to gametocyte prevalence and density on days $O$ and 4 . Early treatment with $A Q$, against sensitive infection, was followed by the lowest gametocytaemia. By contrast, treatment with SP against resistant infection was followed by the highest gametocytaemia. No clear relationship was observed between the density of asexual stages on day $\mathrm{O}$ and the gametocytaemia at any day between days 0 and 14. The epidemiological significance of post-therapeutic gametocytaemia and its possible role in the spread of resistant parasites are underlined. Solutions are proposed in order to avoid or reduce this gametocytaemia.

KEY WORDS : malaria, Plasmodium falciparum, gametocyte, resistance, chloroquine, amodiaquine, sulfadoxine, pyrimethamine, Senegal.

\section{INTRODUCTION}

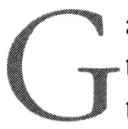
ametocyte is a fascinating stage, responsible for the passage of the malaria parasite from man to anopheline mosquitoes. Its consideration is

\footnotetext{
* Laboratoire de Paludologie, UR Paludologie Afrotropicale, Institut de Recherche pour le Développement, B.P. 1386 Dakar, Sénégal. ** IRD, UR Paludologie Afrotropicale, et Groupe de Recherche sur le Paludisme, Institut Pasteur de Madagascar, B.P. 1274, Antananarivo 101, Madagascar.

Correspondence: Vincent Robert. E-mail: robert@pasteur.mg
}

Résumé : LA GAMÉTOCYTÉMIE CHEZ DES ENFANTS SÉNÉGALAIS EN ACCÈS PALUSTRE SIMPLE TRATTÉS À LA CHLOROQUINE, À L'AMODIAQUINE, OU AU SULFADOXINE + PYRIMÉTHAMINE

La gamétocytémie de Plasmodium falciparum a été étudiée chez 260 enfants sénégalais /âge médian 4 ans, extrêmes 0.5 16 ans) en accès palustres simples traités soit à la chloroquine $(C Q)$, soit à l'amodiaquine $(A Q)$, soit au sulfadoxine+pyriméthamine (SP). La proportion de résistance in vivo pour ces différents traitements a été respectivement de $44 \%$ $16 \%$ et $7 \%$. Les gamétocytes ont été dénombrés par obsenvation microscopique de gouttes épaisses réalisées aux jours 0, 4, 7 et 14 après le traitement. Un pic de gamétocytémie a été observé une semaine après le traitement; aux jours 0,7 , et 74 , les prévalences gamétocytaires ont été de $35 \%$, $73 \%$ et $63 \%$, et les moyennes géométriques des densités ont été de 1.3, 12.5 et 5.6 gamétocytes/ $\mu \mathrm{L}$ de sang. Trois facteurs ont influencé la gamétocytémie : le traitement, l'efficacité du traitement, et la durée des symptômes avant le traitement. La prévalence et la densité gamétocytaires ont été significativement supérieures avec le $S P$ qu'arec la $C Q$, et supérieures avec la $C Q$ qu'avec l'AQ. La prévalence et la densité gamétocytaires ont été significativement supérieures chez les infections résistantes par rapport aux sensibles. Le temps écoulé entre l'apparition des premiers symptômes cliniques et la prise du traitement a été positivement et significativement lié à la prévalence et à la densité gamétocytaires des jours 0 et 4 . Un traitement précoce à la $C Q$ contre une infection sensible a été suivi de la plus faible gamétocytémie. Au contraire, un traitement tardif au SP sur une infection résistante, a été suivi de la gamétocytémie la plus élevée. Il n'a pas été observé de relation évidente entre la densité de stades asexués au jour 0 et la gamétocytémie entre les jours 0 et 14. La signification épidémiologique du pic de gamétocytes post-thérapeutiques et son rôle éventuel dans la dissémination de la résistance des parasites est soulignée. Des solutions sont proposées pour éviter ou réduire celte gamétocytémie.

MOTS CLÉS : paludisme, Plasmodium falciparum, gamétocyte, résistance, chloroquine, amodiaquine, sulfadoxine, pyriméthamine, Sénégal.

not purely biological but can have implications in case management, transmission control, and limiting the spread of resistant parasites.

Parasite commitment to the gametocyte development pathway is irreversible and occurs prior to the merozoite stage developing into the gametocyte (Bruce et al., 1990). The factors that trigger and regulate this switch from asexual to sexual development remain largely unknown (Lobo \& Kumar, 1998). According to what is observed in continuous culture, these factors refer to genetic mechanisms (Graves et al., 1984) and 
to environmental mechanisms, especially when conditions deteriorate (Alano \& Carter, 1990). Completion of Plasmodium falciparum gametocytogenesis, from merozoite to morphologically mature gametocyte, takes 10-12 days in vivo (Thomson, 1911; Sinden et al., 1996), an estimation in accordance with the 10 days observed in vitro (Smalley, 1976). In the blood stream, gametocyte has a half-life of 2.4 days and one gametocyte wave may persist up to three weeks (Smalley \& Sinden, 1977). Plasmodium falciparum gametocytogenesis occurs in the marrow of bones, and consequently the gametocytes commonly observed in the peripheral circulation are morphologically mature.

Recent publications have emphasised that the effect of antimalarials on gametocytes and infectivity for vector mosquitoes requires consideration (Butcher, 1997; Handunnetti et al., 1996; Hogh et al., 1998; Jones, 1997; Robert et al., 1996; Robert \& Trape, 1998). Chloroquine (CQ), amodiaquine (AQ), sulfadoxine (S) and pyrimethamine $(\mathrm{P})$ are schizonticides, are active against young gametocytes in the marrow of bones, and have no effect on the survival of mature gametocytes in the peripheral blood-stream (Smalley \& Sinden, 1977; Butcher, 1997). Induction of gametocytogenesis was demonstrated with subcurative doses of CQ in vivo for P. chabaudi (Buckling et al., 1997), and in vitro for P. falciparum (Buckling et al., 1999).

We have performed a study in children of an endemic area, presenting with uncomplicated malaria, and treated with three antimalarials, which are among the most used in Africa: CQ, AQ and SP. The main objective of this study is to identify the variables linked with the post-therapeutic gametocytaemia.

\section{PATIENTS AND METHODS}

\section{STUDY AREA}

T The study was carried out in the village of Diohine (about $110 \mathrm{~km}$ East of Dakar, Senegal, West Africa), part of the Niakhar area in which the population has been followed for decades for demography and health (Delaunay, 1998). In this area of mesoendemic malaria, transmission occurs from August to October with an annual entomological inoculation rate of 10 (Robert et al., 1998). The parasite rate reaches $80 \%$ in children at the end of the transmission season. Chloroquine resistance has emerged in this area in 1992 and has previously increased the following years. P. falciparum resistance in vivo to chloroquine at RII-RIII levels at day 7 was $10 \%$, $15 \%$ and $17 \%$ in 1993, 1994 and 1995, respectively (Sokhna et al., 1997). The emergence of chloroquine resistance has been associated with a dramatic increase of malaria mortality in the studied population. During the period 1992-1995, malaria mortality averaged 8.2 per thousand per year for children under ten (Trape et al., 1998).

\section{STUDY DESIGN}

Patients were recruited from September to November 1996 when presenting at the dispensary. Children (six months-16 years) were eligible to join the study if they were suffering from uncomplicated $P$. falciparum malaria (> 5,000 parasites $/ \mu \mathrm{L}$ of blood), living in the Niakhar area, not using any specific antimalarial drug for the current period of illness, and if their parents gave informed verbal consent for them to participate in the study. The duration of symptoms before treatment was recorded by asking the children or their parents for how many days the current symptomatic period had lasted. Those with cerebral/complicated malaria or severe anaemia (with packed cell volume $<17 \%$, measured with a centrifuged micro-haematocrite tube) were excluded from the study. The study protocol was approved by the Senegalese Ministry of Health.

\section{TREATMENT REGIMENS}

The children were allocated into three oral treatment groups following the order of inclusion in the study. The treatments were chloroquine (CQ) (chloroquine phosphate, SIPOA Senegal, $25 \mathrm{mg} / \mathrm{kg}$ body weight given over three days: $10 \mathrm{mg} / \mathrm{kg}$ on days 0 and 1 and $5 \mathrm{mg} / \mathrm{kg}$ on day 2), amodiaquine (AQ) (Camoquin ${ }^{\circledR}$, Parke-Davis ${ }^{\mathrm{TM}}, 25 \mathrm{mg} / \mathrm{kg}$ body weight given over three days: $10 \mathrm{mg} / \mathrm{kg}$ on days 0 and 1 and $5 \mathrm{mg} / \mathrm{kg}$ on day 2), or sulfadoxine + pyrimethamine (SP) (Fansidar $^{\circledR}$, Laboratoire Roche ${ }^{\mathrm{TM}}, 25 \mathrm{mg} / \mathrm{kg}$ sulfadoxine + $1.25 \mathrm{mg} / \mathrm{kg}$ pyrimethamine given in a single dose). All children were provided with antipyretics (paracetamol tablets, $30 \mathrm{mg} / \mathrm{kg} /$ day) on days 0 and 1 . Children were observed one hour after treatment, and those who vomited during this period were excluded from the study.

\section{FOLLOW UP OF CHILDREN}

Surveillance was carried out during 14 days after treatment. Thick smears were performed on days $0,4,7$ and 14. Parents were advised to return children to the dispensary at any time if symptoms deteriorated. During the follow-up period if severe malaria and/or clinical failures occurred, a second line treatment was administered, i.e. PS for those initially treated with CQ or AQ, and quinine for those initially treated with SP. At the end of the study, all children who had asexual $P$. falciparum parasitaemia received a second-line treatment. 


\section{MiCROSCOPIC OBSERVATIONS}

Thick blood films were Giemsa-stained and 200 microscopic oil-immersion fields were systematically examined. For each thick film, the mean number of leucocytes per field were evaluated on a sample of fields, gametocyte and asexual parasite densities were calculated assuming an average number of 8,000 leucocytes $/ \mu \mathrm{L}$ of blood. Microscopic examinations were performed blind to treatment regimens.

\section{DATA ANALYSIS}

Geometric means of trophozoites and gametocytes densities were calculated using the geometric mean of Williams [exponential (arithmetic mean $\left(\log _{e}\left(x_{i}+1\right)\right)$ )-1]. Discrete data were compared between groups using either the chi-square test or the Fisher's exact test. Differences between group means were analysed using non parametric Mann-Whitney U-test or Kruskal-Wallis test. Various gametocyte prevalences depending on the duration of symptoms before treatment were compared using the tendency chi-square test.

\section{RESULTS}

A total of 319 children with uncomplicated malaria were included in the study on day 0 and allocated into the three treatment groups ( $\mathrm{n}=$ 107 with CQ; $\mathrm{n}=106$ with $\mathrm{AQ}$, and $\mathrm{n}=106$ with SP). Fifty three children (17\%) were lost to follow-up or excluded: 20 vomited, 11 travelled, seven experienced clinical failures and received second line treatment, seven refused a blood test, five had an illegible thick smear at either days 4,7 or 14 , and three had no measure of haematocrite. Twenty-three among them had been treated with CQ, 19 with $\mathrm{AQ}$, and 11 with SP. Hence the results presented here involve 266 children with a mean age $\pm \mathrm{SD}=5.09 \pm 3.54$ (median $=4$; range = six months- 16 years) distributed as $84 \mathrm{CQ}, 87 \mathrm{AQ}$ and 95 SP. At day 0, the children in these three treatment groups did not differ for mean age, duration of symptoms before treatment, trophozoite density, gametocyte density, sex-ratio or gametocyte prevalence $(0.14<P<0.74)$.
The overall prevalences of in vivo resistant infections were $44 \%, 16 \%$ and $7 \%$ at day 14 after treatment with CQ, AQ and SP, respectively (Table I). The efficacy of treatment was not linked with the age of children (the means of ages with sensitive infections versus resistant infections were not different; MannWhitney $U$-test $P=0.67$ for the three treatments; $P=$ 0.81 for CQ; $P=0.49$ for AQ; $P=0.35$ for SP).

Considering the total number of observations $(n=266)$ the gametocytaemia presented a peak after treatment. At days $0,4,7$, and 14 the gametocyte prevalences were $35 \%, 72 \%, 73 \%$ and $63 \%$; the geometric means of gametocyte densities were 1.3, 7.4, 12.5 and $5.6 / \mu \mathrm{L}$ of blood.

\section{EFFECT OF TREATMENT ON GAMETOCYTAEMIA}

Post-therapeutic gametocytaemia significantly differed between treatments. It was higher with SP than with CQ, and higher with CQ than with AQ (Fig. 1). Gametocyte prevalences peaked at $59 \%$ and $69 \%$ on day 4 for $\mathrm{AQ}$ and CQ, respectively, and $94 \%$ on day 7 for SP. Geometric mean densities of gametocytes $/ \mu \mathrm{L}$ of blood peaked at 3.6 on day 4 for AQ, and at 10.1 and 43.8 on day 7 for CQ and SP, respectively. General differences in gametocyte densities were observed between treatment groups at each follow-up times (by Kruskal-Wallis test with $\mathrm{df}=2, P$ always $<10^{-4}$ on days 4,7 and 14). Areas under these curves of densities between days 0 and 14 are 2.03 times higher with CQ than AQ, and 7.90 times higher with SP than AQ.

\section{EFFECT OF PARASITOLOGICAL EFFICACY OF TREATMENT ON GAMETOCYTAEMIA}

The parasitological response of infections after treatment was another factor influencing gametocytaemia. Gametocyte prevalence was higher in resistant infection than in sensitive ones; this was systematically observed on days $0,4,7$ and 14 for all three treatments (Table II) and significant differences were observed with CQ and AQ on day 7. When considering only children without gametocyte on day 0 , significant differences were observed between sensitive and resistant infections with CQ on day 7 and with AQ on days 4, 7 and 14 (Fig. 2) ( $P$ always $<0.03$ by Fisher's

\begin{tabular}{|c|c|c|c|c|c|c|c|c|}
\hline \multirow[b]{2}{*}{ Treatment } & \multicolumn{8}{|c|}{ Number of infections } \\
\hline & $\mathbf{N}$ & Sensitive & RI day 7 & RI day 14 & RII & RIII & Total $\mathbf{R}$ & $\% \mathbf{R}$ \\
\hline CQ & 84 & 47 & 2 & 12 & 23 & 0 & 37 & 44.0 \\
\hline $\mathrm{AQ}$ & 87 & 73 & 0 & 6 & 8 & 0 & 14 & 16.1 \\
\hline $\mathrm{SP}$ & 95 & 88 & 0 & 4 & 3 & 0 & 7 & 7.4 \\
\hline Total & 266 & 208 & 2 & 22 & 34 & 0 & 58 & - \\
\hline
\end{tabular}

Table I. - Number of P. falciparum infections, according to treatments $(\mathrm{CQ}=$ chloroquine, $\mathrm{AQ}=$ amodiaquine, $\mathrm{SP}=$ sulfadoxine + pyrimethamine) and to parasitological responses $(\mathrm{R}=$ resistant $)$. 

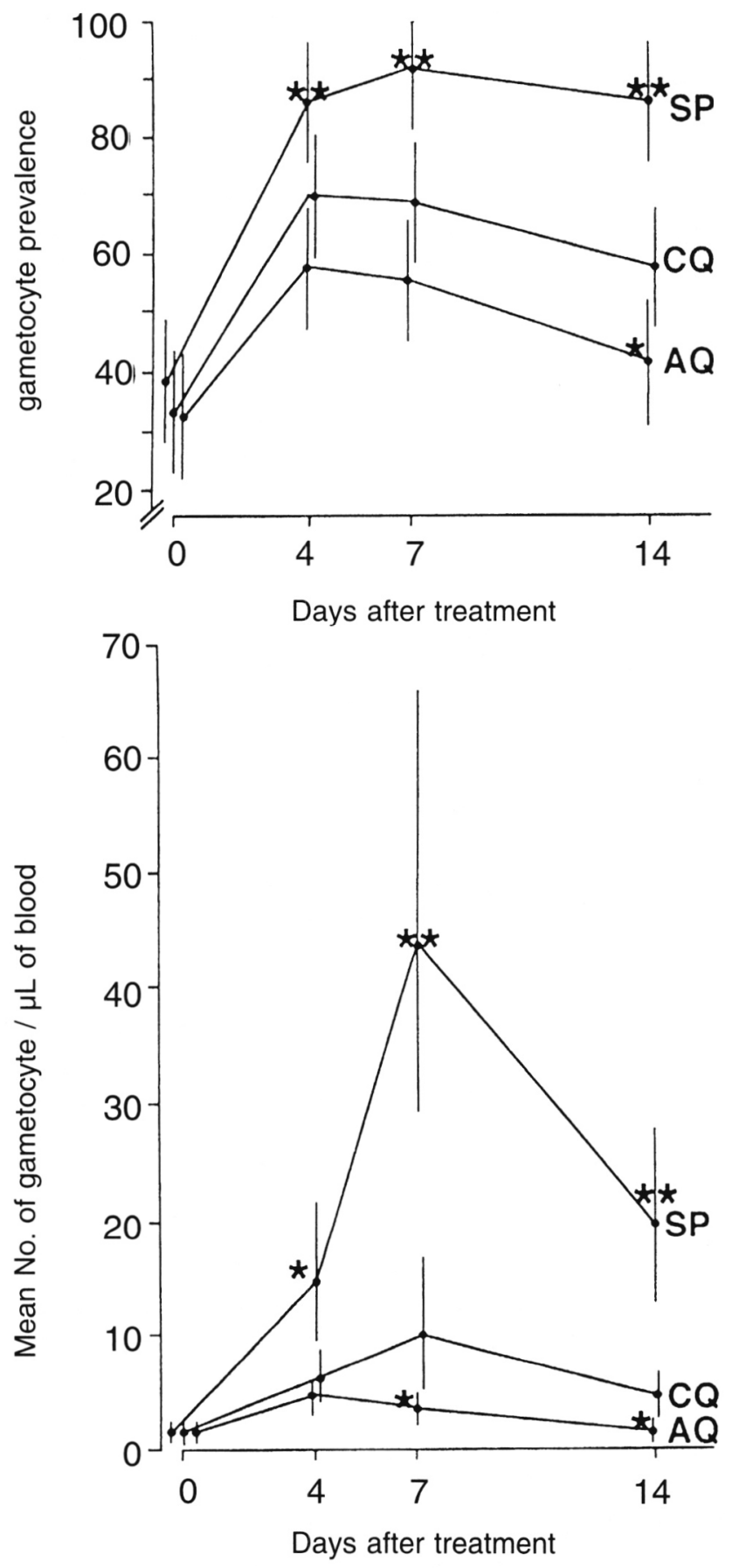

Fig. 1. - Prevalence (\%) and geometric mean of Williams of Plasmodium falciparum gametocytes for patients in simple malaria access treated with different drugs (8 patients with chloroquine CQ, 87 patients with amodiaquine AQ, and 95 patients with sulfadoxine plus pyrimethamine SP). Above spots of AQ and SP curves, one asterisk indicates a $P$ value $<0.05$ and two asterisks indicate a $P$ value $<0.005$, by comparing against CQ on the same day with Fisher's exact test (prevalence) or Mann-Whitney $U$-test (density). Bars indicate the $95 \%$ confidence interval.
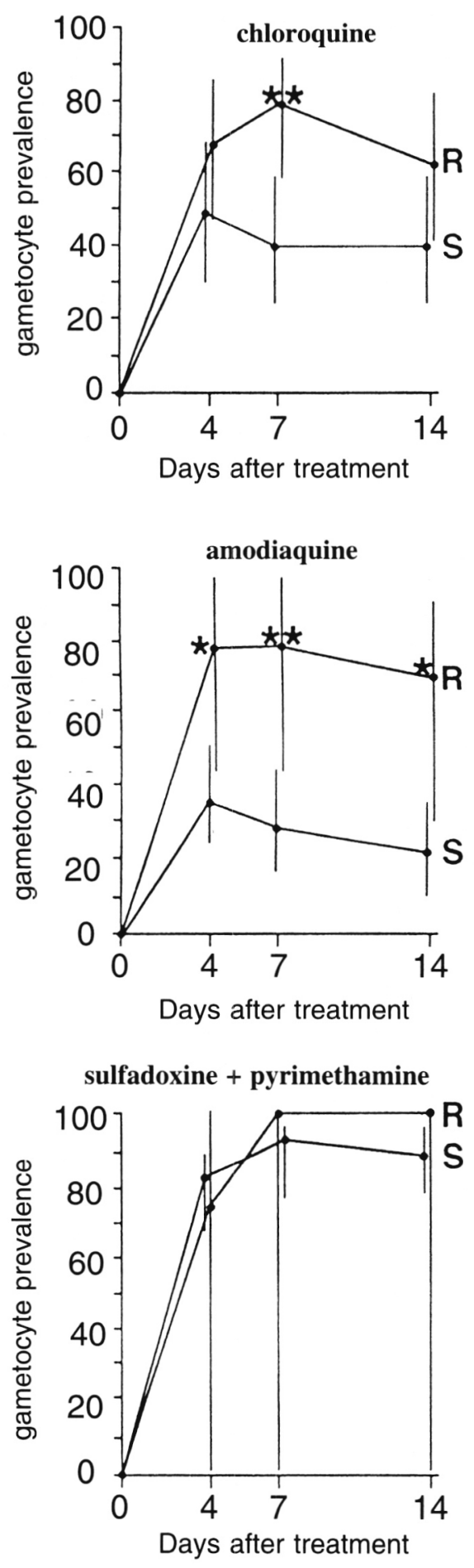

Fig. 2. - Prevalence of P. falciparum gametocytes for patients in simple malaria access, without gametocytes at day 0 , treated with different drugs ( 57 patients with chloroquine, 58 patients with amodiaquine, and 58 patients with sulfadoxine plus pyrimethamine). Above spots of resistant $(\mathrm{R})$ infections, one asterisk indicates a $P$ value $<0.05$ and two asterisks indicate a $P$ value $<0.005$, by comparing against sensitive (S) infections on the same day with Fisher's exact test. Bars indicate the $95 \%$ confidence interval. 
exact test). The prevalence of gametocytaemia was not significantly different between the resistance levels RI or RII (results on day 7 are presented in Table III; results on days 4 and 14 were similar but data are not shown).

Gametocyte density was higher in resistant infections than in sensitive ones; this was systematically observed on days 4,7 and 14 with the three treatments and significant differences were observed with $C Q$ and $A Q$ on days 7 and 14 (Table IV). Furthermore, gametocyte density was higher in RII than in RI infections although this difference was not significant (Table III). After a Log $(x+1)$ transformation of trophozoite and gametocyte densities, trophozoite density on day 4 was positively correlated with the gametocyte density on day 7
( $\mathrm{r}=0.151, \mathrm{n}=266, P=0.013)$ and day $14(\mathrm{r}=0.168$, $\mathrm{n}=266, P=0.006)$; such a correlation was also observed between trophozoite density on day 7 and gametocyte density on day $14(\mathrm{r}=0.137, \mathrm{n}=266, P=0.026)$.

\section{EFFECT OF DURATION OF SYMPTOMS BEFORE TREATMENT ON GAMETOCYTAEMIA}

The median of the duration of symptoms reported by the children or their parents at the beginning of treatment (day 0) was three days (mean $\pm \mathrm{SD}=3.45 \pm 4.26$; range: $0-60$ ). The mean $( \pm \mathrm{SD}$ ) duration of symptoms before treatment among children with gametocytes on day 0 was $4.85 \pm 6.68$; among children without gametocytes on day 0 it was $2.70 \pm 1.57\left(P<10^{-4}\right.$, MannWhitney $U$-test); these differences were observed in the

\begin{tabular}{|c|c|c|c|c|c|c|c|c|c|c|}
\hline \multirow[b]{2}{*}{ Treatment } & \multirow{2}{*}{$\begin{array}{c}\text { Parasitological } \\
\text { response }\end{array}$} & \multirow[b]{2}{*}{$\mathbf{n}$} & \multicolumn{8}{|c|}{ Gametocyte prevalence at } \\
\hline & & & day 0 & $\boldsymbol{P}$ & day 4 & $\boldsymbol{P}$ & day 7 & $\boldsymbol{P}$ & day 14 & $P$ \\
\hline CQ & $\begin{array}{l}\mathrm{S} \\
\mathrm{R}\end{array}$ & $\begin{array}{l}47 \\
37\end{array}$ & $\begin{array}{l}29.8 \\
35.1\end{array}$ & 0.64 & $\begin{array}{l}61.7 \\
78.4\end{array}$ & 0.15 & $\begin{array}{l}55.3 \\
83.8\end{array}$ & 0.009 & $\begin{array}{l}48.9 \\
70.2\end{array}$ & 0.07 \\
\hline $\mathrm{AQ}$ & $\begin{array}{l}\mathrm{S} \\
\mathrm{R}\end{array}$ & $\begin{array}{l}73 \\
14\end{array}$ & $\begin{array}{l}32.9 \\
35.7\end{array}$ & 0.99 & $\begin{array}{l}54.8 \\
78.6\end{array}$ & 0.57 & $\begin{array}{l}49.3 \\
85.7\end{array}$ & 0.02 & $\begin{array}{l}40.0 \\
64.3\end{array}$ & 0.08 \\
\hline SP & $\begin{array}{l}S \\
\mathrm{R}\end{array}$ & $\begin{array}{r}88 \\
7\end{array}$ & $\begin{array}{l}38.6 \\
42.9\end{array}$ & 0.99 & $\begin{array}{l}86.4 \\
85.7\end{array}$ & 0.99 & $\begin{array}{r}93.2 \\
100.0\end{array}$ & 0.99 & $\begin{array}{l}86.4 \\
85.7\end{array}$ & 0.99 \\
\hline
\end{tabular}

Table II. - P. falciparum gametocyte prevalence (\%), according to treatments (CQ = chloroquine, $\mathrm{AQ}=$ amodiaquine, $\mathrm{SP}=$ sulfadoxine + pyrimethamine) and to parasitological responses ( $\mathrm{S}=$ sensitive, $\mathrm{R}=$ resistant $)$. The $P$ values were obtained by the Fisher's exact test.

\begin{tabular}{|c|c|c|c|c|c|c|}
\hline \multirow[b]{2}{*}{ Treatment } & \multirow[b]{2}{*}{ Type of resistance } & \multirow[b]{2}{*}{$\mathbf{n}$} & \multicolumn{4}{|c|}{ Gametocyte } \\
\hline & & & Prevalence $(\%)$ & $\boldsymbol{P}$ & Density & $\boldsymbol{P}$ \\
\hline \multirow[t]{2}{*}{ CQ } & RI & 14 & 13/14 (93) & \multirow[t]{2}{*}{0.17} & 21.4 & \multirow[t]{2}{*}{0.66} \\
\hline & RII & 23 & $18 / 23(78)$ & & 25.1 & \\
\hline \multirow[t]{2}{*}{$\mathrm{AQ}$} & RI & 6 & $4 / 6 \quad(67)$ & \multirow[t]{2}{*}{0.38} & 12.3 & \multirow[t]{2}{*}{0.89} \\
\hline & RII & 8 & $8 / 8 \quad(100)$ & & 16.8 & \\
\hline \multirow[t]{2}{*}{$\mathrm{SP}$} & RI & 4 & $4 / 4 \quad(100)$ & \multirow[t]{2}{*}{0.99} & 72.8 & \multirow[t]{2}{*}{0.99} \\
\hline & RII & 3 & $3 / 3 \quad(100)$ & & 150.6 & \\
\hline
\end{tabular}

Table III. - Comparison of P. falciparum gametocyte prevalence and density for resistant infections, on day 7 after treatment, according to the type of resistant infections (RI = resistant infection, level 1; RII = resistant infection, level 2). The $P$ values were obtained by Fisher's exact test (prevalence) or Mann-Whitney $U$ test (density).

\begin{tabular}{|c|c|c|c|c|c|c|c|c|c|c|}
\hline \multirow[b]{2}{*}{ Treatment } & \multirow{2}{*}{$\begin{array}{l}\text { Parasitological } \\
\text { response }\end{array}$} & \multirow[b]{2}{*}{$\mathbf{n}$} & \multicolumn{8}{|c|}{ Gametocyte density at } \\
\hline & & & day 0 & $\boldsymbol{P}$ & day 4 & $\boldsymbol{P}$ & day 7 & $\boldsymbol{P}$ & day 14 & $p$ \\
\hline \multirow[t]{2}{*}{ CQ } & S & 47 & 1.0 & 0.51 & 5.4 & 0.26 & 4.9 & 0.0039 & 2.0 & 0.0094 \\
\hline & $\mathrm{R}$ & 37 & 1.6 & & 8.9 & & 23.6 & & 8.3 & \\
\hline \multirow[t]{2}{*}{$\mathrm{AQ}$} & S & 73 & 1.6 & 0.84 & 3.3 & 0.27 & 2.4 & 0.027 & 1.0 & 0.0056 \\
\hline & $\mathrm{R}$ & 14 & 0.6 & & 5.6 & & 14.7 & & 7.3 & \\
\hline \multirow[t]{2}{*}{ SP } & S & 88 & 1.2 & 0.91 & 14.6 & 0.93 & 44.1 & 0.24 & 17.8 & 0.10 \\
\hline & $\mathrm{R}$ & 7 & 0.7 & & 15.2 & & 99.5 & & 48.1 & \\
\hline
\end{tabular}

Table IV. - Geometric mean of $P$. falciparum gametocyte density, according to treatments $(\mathrm{CQ}=$ chloroquine, $\mathrm{AQ}=$ amodiaquine, $\mathrm{SP}=$ sulfadoxine + pyrimethamine $)$ and to parasitological responses $(\mathrm{S}=$ sensitive, $\mathrm{R}=$ resistant $)$. The $P$ values were obtained by the MannWhitney $U$-test. 


\begin{tabular}{ccccc}
\hline \multirow{2}{*}{$\begin{array}{c}\text { Gametocyte } \\
\text { prevalence at }\end{array}$} & Days 0 or - 1 & Day - & Day - 3 & $\leq$ days - \\
\hline
\end{tabular}

Table V. - P. falciparum gametocyte prevalence (\%) at days 0 and 4 related to the duration of symptoms before treatment for the whole 266 children of the study. The $P$ values were obtained by the chi-square test for linear trend.

three treatment groups ( $P$ always $<0.003)$. The gametocyte prevalence increased with duration from zero to four days (Table $V$, in which duration $\geq 4$ days were presented together because a plateau was observed for such durations of symptoms; data not shown) but not on days 7 and $14(P=0.14$ and $P=0.27$, Mann-Whitney $U$-tests).

Gametocyte densities on days 0 and 4 were correlated with the duration of symptoms before treatment $(\mathrm{r}=$ $0.131, \mathrm{n}=266, P=0.03$ on day $0 ; \mathrm{r}=0.145, \mathrm{n}=266$, $P=0.02$ on day 4$)$; such a relationship was not observed on days 7 and $14(P=0.12$ and $P=0.81$, respectively). On day 4 , geometric mean of gametocyte density calculated with the positive values only increased from $11.1 / \mu \mathrm{L}$ when the duration of symptoms was 0 or 1 day to $30.6 / \mu \mathrm{L}$ when the duration of symptoms was $\geq 4$ days, i.e. a 2.8 fold increase.

\section{LACK OF EFFECT OF OTHER VARIABLES ON GAMETOCYTAEMIA}

Asexual parasite density on day 0 was linked with the gametocyte prevalence on day 0 : geometric mean of asexual parasites on day 0 was $47,893 / \mu \mathrm{L}$ for children without gametocyte on day 0 versus 34,534 for children positive for gametocytes $(P=0.002$; Mann-Whitney $U$-test). This relationship was not observed between asexual parasite density on day 0 and gametocyte prevalences on day $4(P=0.43)$, day $7(P$ $=0.64)$ and day $14(P=0.08)$. Asexual parasite density on day 0 was not correlated with the gametocyte density on day $0:(\mathrm{r}=0.048, \mathrm{n}=266, P=0.43)$, day 4 $(\mathrm{r}=-0.076, P=0.22)$, day $7(\mathrm{r}=-0.036, P=0.56)$ and day $14(\mathrm{r}=-0.010, P=0.86)$. Such analysis, stratified either in relation to therapeutic efficacy (sensitive versus resistant, whatever treatment performed), or in relation to treatment and therapeutic efficacy, led to the same conclusions ( $P$ always $>0.05$ ); a Log transformation of gametocyte density did not change these results.

The ratio of circulating sexual-to-asexual-form densities on day 0 was not significantly correlated with host age $(\mathrm{r}=-0.113, \mathrm{n}=266, P=0.065)$.

Haematocrit on day 0 was negatively correlated with gametocyte density on day $0(\mathrm{r}=-0.255, \mathrm{n}=266, P$ $<10^{-4}$ ) as well as with duration of symptoms before treatment $\left(\mathrm{r}=-0.270, \mathrm{n}=266, P<10^{-4}\right)$.

\section{DISCUSSION}

$\Lambda$ fter treatment of children with uncomplicated malaria, a wave of gametocytes has been observed. In our study, three factors were found to influence gametocytaemia: the treatment, the efficacy of treatment, and the duration of symptoms before treatment. Firstly, gametocyte prevalence and density significantly appeared higher in children treated with SP than with CQ, and higher with CQ than with $A Q$. These results agree with previous studies comparing SP and CQ (Puta \& Manyando 1997; Hogh et al., 1998) and highlight the advantage of $\mathrm{AQ}$ in this aspect. Secondly, gametocyte prevalence and density were higher in resistant than in sensitive infections. That was verified for the three treatment regimens and on any day after treatment. Even on day 0 gametocyte prevalence was found to be higher in resistant infections than in sensitive ones; although statistically nonsignificant, this observation has previously been made twice in Senegal (Robert et al., 1996; Robert \& Trape, 1998). Unlike to what was observed by Hogh et al. (1998) the gametocytaemia in SP-resistant infections was higher than in -sensitive ones. Thirdly, the delay between the first appearance of clinical symptoms and treatment was positively and significantly linked to gametocyte prevalence and density. This result strongly supports the idea that an early treatment with an efficient antimalarial greatly reduces gametocytaemia, and hence could reduce the transmission. Unlike to previous study (Robert et al., 1996), no significant differences between gametocyte prevalence and density were observed between RI and RII; this may be due to low number of observations (Table III).

The relationship between density of asexual stage and subsequent gametocytaemia is unclear. No correlation was observed between asexual parasite density on day 0 and gametocyte density on day 0 nor gametocyte prevalence or density at any other day up to day 14 . The actual correlation coefficients between trophozoite density (on day 4 or 7 ) with gametocyte density (on days 7 or 14) are all small $(<0.17)$ and do not suggest a major relationship between trophozoite density and subsequent gametocyte densities. Our data are consistent with the idea that gametocytogenesis and asexual growth operate as two distinct pathways with 
very few communication. This situation is puzzling because each gametocyte is always generated from an asexual parasite; it could be a consequence of numerous interactions such as relative timing and longevity of gametocytes, symptomatic patients or immune responses, and mixed infections with variable production of gametocytes relative to asexual stages in each infection.

What is the impact of the post-therapeutic gametocytaemia in terms of transmission? Higher gametocyte densities are strongly associated with greater infectivities to mosquitoes (Carter \& Graves, 1988). Antimalarial drugs often have an effect (positive or negative) on gametocyte infectivity and/or parasite development in the anophelines: pyrimethamine is clearly sporonticidal, and there are some indications of such an effect for sulfadoxine; the latter might increase gametocytogenesis in drug-resistant lines of $P$. gallinaceum (Butcher, 1997); CQ enhances gametocyte infectivity, whilst SP reduces it (Hogh et al., 1998). We investigated infectivity of gametocytes of patients taken at day 7 after chloroquine treatment (Robert et al., 2000): the relative risk for patients with chloroquine-resistant infection to infect anophelines was 4.07 higher than with sensitive infection. This result demonstrated the importance of the peak of gametocytaemia after chloroquine treatment and its consequence in the increase of transmission.

In Niakhar area as in other parts of the Sahel, anophelines vectors are abundant only a few weeks each year. As a consequence, transmission is relatively low and strictly seasonal. Protective immunity is slowly acquired and a high proportion of new infections leads to clinical attacks. In such context, post-therapeutic gametocytaemia may represent a high proportion of the parasites reservoir. Furthermore, due to the dramatic differences in post therapeutic gametocytaemia between CQ sensitive and CQ resistant strains, drug pressure is likely to rapidly increase both the prevalence of $P$. falciparum resistant strains, the sporozoite rate of anopheline vectors and thus the level of malaria transmission. The most severe consequences of this succession of events are expected to occur in areas where malaria is unstable and only a fraction of the population is infected every year. A dramatic increase in malaria mortality has been documented through hospital and dispensary records in recent years in Saint-Louis region, in Northern Senegal. Here we hypothesise that this could be due to an increase in malaria transmission related not only to high rains and water management schemes, but also to an increase in the prevalence of post-therapeutic gametocytaemia caused by the spread of chloroquine resistance. Chloroquine resistance increases the fatality rates of malaria attacks, as observed since 1992 in Niakhar area (Trape et al., 1998). Its maximum impact is however expected to occur in areas of even lower transmission since it is only for very low values of the entomological inoculation rate that the incidence of malaria attacks is function of transmission intensity (Trape \& Rogier, 1996).

We believe that our study highlights the importance of preventing post-therapeutic gametocytaemia both for preserving drug efficacy and avoiding an increase in malaria transmission in areas with low transmission. The combined therapy strategy using artemisinin and its derivatives which are strongly effective to reduce both gametocytaemia and malaria transmission would be particularly relevant in this region of Africa(White, 1998; von Seidlein et al., 2001; Targett et al., 2001).

\section{ACKNOWLEDGEMENTS}

T This study was supported by a grant from the Ministère de la Coopération, France. We are grateful to the villagers of Diohine for their active participation and continuing collaboration in the project. Hubert Bassène and Ibou Cissé provided an excellent technical support. We thank Ric Paul, Jean-Yves Le Hesran and André Spiegel for valuable comments on the manuscript. SIPOA and Park Davis kindly provided chloroquine and amodiaquine, respectively.

\section{REFERENCES}

Alano P. \& Carter R. Sexual differentiation in malaria parasites. Annual Review of Microbiology, 1990, 44, 429-449.

Bruce M.C., Alano P., Duthie S. \& Carter R. Commitment of the malaria parasite Plasmodium falciparum to sexual and asexual development. Parasitology, 1990, 100, 191-200.

Buckling A., Ranford-Cartwright L.C., Miles A. \& Read A.F. Chloroquine increases Plasmodium falciparum gametocytogenesis in vitro. Parasitology, 1999, 118, 339-346.

Buckling A.G.J., Taylor L.H., Carlton J.M.R. \& Read A.F. Adaptative changes in Plasmodium transmission strategies following chloroquine chemotherapy. Proceeding of the Royal Society, London B, 1997, 264, 553-559.

Butcher G.A. Antimalarial drugs and the mosquito transmission of Plasmodium. International Journal for Parasitology , 1997, 27, 975-987.

Carter R. \& Graves P. Gametocytes. In: Malaria, priciples and practice of malariology. Wernsdorfer W.H. \& McGregor I. (eds), Edinburgh, Churchill Livingstone, 1988, 709-734.

Delaunay V. La situation démographique et épidémiologique dans la zone de Niakhar au Sénégal, 1984-1996. Orstom (ed). Dakar, 1998, 132 pp.

Graves P.M., Carter R. \& McNeill K.M. Gametocyte production in clones lines of Plasmodium falciparum. American Journal of Tropical Medicine and Hygiene, 1984, 45, 1045-1050. 
Handunnetti S.M., Gunewardena D.M., Pathirana P.P.S.L., EKanayake K., WeERasinghe S. \& Mendis K.N. Features of recrudescent chloroquine-resistant Plasmodium falciparum infections confer a survival advantage on parasites and have implications for disease control. Transactions of the Royal Society of Tropical Medicine and Hygiene, 1996, 90, 563-567.

Hogh B., Gamage-Mendis A., Butcher G.A, Thomson R., Begtrup K., Mendis C., Enosse S. M., Dogedge M., Barreto J., ELING W. \& SindEN R.E. The differing impact of chloroquine and pyrimethamine/sulfadoxine upon the infectivity of malaria species to the mosquito vector. American Journal of Tropical Medicine and Hygiene, 1998, 58, 176-182.

JONES T.R. Quantitative aspects of the relationship between the sickle-cell gene and malaria. Parasitology, 1997, 13, 107-111.

Koella J.C. Costs and benefits of resistance against antimalarial drugs. Parasitology Today, 1998, 14, 360-364.

Lobo C.A. \& Kumar N. Sexual differentiation and development in malaria parasite. Parasitology Today, 1998, 14, 146-150.

Puta C. \& Manyando C. Enhanced gametocyte production in Fansidar-treated Plasmodium falciparum malaria patients: implications for malaria control programmes. Tropical Medicine and International Health, 1997, 3, 227-229.

Robert V., Awono-Ambéné H.P., Le Hesran J.Y. \& Trape J.F Gametocyte and infectivity to mosquito of patients with uncomplicated Plasmodium falciparum malaria attacks treated with chloroquine or sulphadoxine plus pyrimethamine. American Journal of Tropical Medicine and Hygiene, 2000, 62, 210-216.

Robert V., Dieng H., Lochouarn L., Traoré S.F., Trape J.F., SimONDON F. \& FonTEnille D. La transmission du paludisme dans la zone de Niakhar, Sénégal. Tropical Medicine \& International Health, 1998, 3, 667-6777.

Robert V., Molez J.F. \& Trape J.F. Gametocytes, chloroquine pressure, and the relative parasite survival advantage of resistant strains of falciparum malaria in West Africa. American Journal of Tropical Medicine and Hygiene, 1996, 55, 350-351.

Robert V. \& Trape J.F. Dynamiques de la gamétocytémie à Plasmodium falciparum en fonction de la réponse thérapeutique à la chloroquine en zone de mésoendémie palustre. Bulletin de la Société de Pathologie Exotique 1998, 91 , 142-145.

Sinden R.E., Butcher G.A., Billker O. \& Fleck S.L. Regulation of infectivity of Plasmodium to the mosquito vector. Advances in Parasitology, 1996, 38, 53-117.

SMALLEY M.E. Plasmodium falciparum gametocytogenesis in vitro. Nature, 1976, 264, 271-272.

SMALley M.E. \& Sinden R.E. Plasmodium falciparum gametocytes: their longevity and infectivity. Parasitology, 1977, 74, 1-8.

Sokhna C.S., Molez J.F., Ndiaye P., Sane B. \& Trape J.F. Tests in vivo de chimiosensibilité de Plasmodium falciparum à la chloroquine au Sénégal : évolution de la résistance et estimation de l'efficacité thérapeutique. Bulletin de la Société de Pathologie Exotique, 1997, 90, 83-89.
Targett G., Drakeley C., Jawara M., von Seidlein L., Coleman R., DeEn J., Pinder M., Doherty T., Sutherland C., WalRaVEn G., Milligan P. Artesunate reduces but does not prevent posttreatment transmission of Plasmodium falciparum to Anopheles gambiae. Journal of Infectious Diseases, 2001, 183, 1254-1259.

TRAPE J.F. \& ROGIER C. Combatting malaria morbidity and mortality by reducing transmission. Parasitology Today , 1996, 12, 236-240.

Trape J.F., Pison G., Preziosi M.P., Enel C., Desgrées du lou A., Delaunay V., Samb B., Lagarde E., Molez J.F. \& Simondon J.F. Impact of chloroquine resistance on malaria mortality. Comptes Rendus de l'Académie des Sciences, Paris, Life Sciences, 1998, 321, 689-697.

Thomson D. A research into the production, life and death of crescents in malignant tertian malaria, in treated and untreated cases, by an enumerative method. Annals of Tropical Medicine and Parasitology, 1911, 5, 57-82.

von Seidlein L., Jawara M., Colemean R., Doherty T., WalRAVEN G. \& TARgetT G. Parasitaemia and gametocytaemia after treatment with chloroquine, pyrimethamine/sulfadoxine, and pyrimethamine/sulfadoxine combined with artesunate in young Gambians with uncomplicated malaria. Tropical Medicine and International Health, 2001, 6, 9298.

White N. Preventing antimalarial drug resistance through combinations. Drug Resistance Updates, 1998, 1, 3-9.

Reçu le 27 mars 2001 Accepté le 6 juin 2001 